\section{Historical review}

\title{
The control of syphilis, a contemporary problem: a historical perspective
}

\author{
T Green, M D Talbot, R S Morton
}

The control of syphilis in the United Kingdom and United States has been managed in different ways in each country over the course of the last century. Older more established measures including contact tracing, serological surveillance, and health education strategies together with effective antibiotic therapy have had some success. However, changing social structures on both sides of the Atlantic Ocean have brought newer mathematical and epidemiological methods to the fore. This review looks at the past management of syphilis control in the United Kingdom and United States, and speculates on future prospects for disease management in these countries. (Sex Transm Inf 2001;77:214-217)

Keywords: syphilis; United Kingdom; United States

\section{Introduction}

Throughout the developed world the reported incidence of syphilis has fallen steadily over the past four decades. This decrease has been attributed to a range of measures including access to specialist clinics, accurate diagnostic tests, effective antibiotic therapy and contact tracing procedures.

Historically, interest in syphilis has waned as case numbers have fallen and this holds true today. However, the disease is still problematic in parts of the United States, and recent UK outbreaks, although small, have brought the issue of disease control sharply back into focus. This review looks at how the public health threat of syphilis has been assessed and managed by the United Kingdom and United States since the early 1900s and suggests how past lessons may shape future strategies.

\section{Establishing control of syphilis in the United Kingdom \\ A BEGINNING (1917-39)}

The 1916 report of a Royal Commission on Venereal Diseases heralded syphilis control endeavours in the United Kingdom. Government money was provided for the establishment of local health authority venereal disease clinics that were part of a nationwide network of diagnostic and treatment facilities. Public open access, free confidential treatment, voluntary attendance, and service availability at all times to match patient needs were crucial requirements. In all, 117 clinics had been established by the end of 1917 and the network expanded subsequently to 230 facilities.

These clinics provided trained personnel offering early scientific diagnosis, appropriate treatment, and routine follow up. Arrangements were also made for the attendance, testing, and treatment of sexual partners. These measures combined with public health education and routine hospital screening by the Wassermann test led to an overall fall in the prevalence of syphilis. Improvements were seen particularly in the figures for early infectious disease, congenital infection, and mortality. By 1936 the standard mortality rate for general paralysis of the insane was approximately one third of that seen in 1914 while for tabes dorsalis it was just over half. ${ }^{1}$

CONTROL IS ESTABLISHED (1940-55)

Thousands of infected service personnel were treated during the second world war. The postwar epidemic peak indicated the enormity of infection introduced into the civilian population on demobilisation. Penicillin became available from 1943, initially as an adjunct to, and then as a replacement for, arsenic and bismuth therapy.

Contact tracing was intensified and applied both to family and sexual contacts with the aim of controlling congenital as well as acquired syphilis.

Case finding was also increased by the introduction of serological screening for blood donors, hospital inpatients, and prisoners. Antenatal syphilis screening was introduced for every pregnancy. As many as one in 100 pregnant women were seropositive with multiparous women particularly at risk in the early post-war years. Expectant mothers were treated as inpatients with penicillin and their babies declared syphilis free after testing at 1 and 3 months of age. ${ }^{23}$

These approaches, together with public education about the prevalence and problems of syphilis, reduced disease to an apparently irreducible low level. It was suggested that elimination would be only be achieved by combining nationwide premarital and antenatal screening with adequate treatment of early acquired infection. ${ }^{45}$

MAINTAINING CONTROL (1956-2000)

The above strategies continued to be deployed in an attempt to control syphilis and penicillin remained (and is still) the treatment mainstay.

The number of reported cases in the $1950 \mathrm{~s}$ declined steadily, but there was a sudden rise in 
1961, possibly caused by serological confusion with old yaws in the immigrant AfroCaribbean population. A further peak occurred in 1965 characterised by heterosexual men of Asian origin in large UK cities. ${ }^{6}$ Homosexual men then featured prominently in the figures through the late 1960s and 1970 s and by 1978 accounted for almost $58 \%$ of all primary and secondary syphilis cases in England and Wales and $76 \%$ of cases for the London area. ${ }^{7}$ More recently, however, statistics for 1994-6 show only $25 \%$ of syphilis to be homosexually acquired. ${ }^{8}$ Behavioural changes precipitated by the health education drive in the wake of HIV may have played a part in this decline, although there is evidence from rising STI figures to suggest that initial safe sex practices have not been maintained. ${ }^{9}$

The total number of infectious syphilis cases reported from genitourinary medicine clinics in England and Wales has fallen from 1873 in 1977 to 130 in $1995 .{ }^{10}$ However, between 1997 and 1998, a heterosexual outbreak of syphilis in Bristol involved upwards of 45 cases, most of whom acquired their infection in the United Kingdom. ${ }^{11-13}$ Across the United Kingdom as a whole a substantial proportion of infections have been linked to foreign travel, particularly to eastern Europe and the Russian Federation where syphilis is on the increase ${ }^{14-16}$ Four of the female cases in Bristol were identified by routine antenatal screening and a recently published report has recommended that antenatal testing for syphilis should continue. ${ }^{17}$ There has also been a recent outbreak in Manchester predominantly affecting homosexual men, a number of whom were also HIV positive $^{18}$ and also a cluster of cases in Brighton, again involving homosexual men. ${ }^{19}$

\section{Establishing control of syphilis in the United States}

A MISSED OPPORTUNITY REDEEMED (1917-41) A mass serological survey in 1917 showed that nearly $6 \%$ of the first world war service "enlistees" had reactive syphilis serology. ${ }^{20}$ However, despite the post-war establishment of a venereal disease (VD) division in the US public health service there was no useful follow up. Surgeon-general Thomas Parran stated that "Congress believed the spirochete had stayed behind in the trenches" and in 1936 he mounted a classic public health media campaign. The message was that syphilis was common, accounting for $10 \%$ of the public drug bill, one in 14 of all mental hospital admissions, and 20000 annual deaths. ${ }^{21}$

Parran's success was spectacular and the resulting public awareness led congress to pass a bill in 1938 funding local VD control programmes and legislating for premarital and prenatal serological testing. The number of clinics almost trebled from 1122 to 3088 between 1938-41; many were designated "rapid treatment centres" where a 21 day course of an arsenical was given on an outpatient basis. Thus, when the United States entered the second world war at the end of 1941 there was a nationwide clinic network able to deal with the expected wartime epidemic.

CONTROL IS ESTABLISHED (1942-55)

US forces medical staff dealt well with infected service personnel at home and abroad. Useful liaisons with civilian medical personnel were fostered in the UK and contact tracing was encouraged. In 1943, US manufactured penicillin became available, first to infected service personnel and subsequently to civilians attending the rapid treatment centres. The existing premarital and prenatal mass screening programmes were augmented by pre-employment and blood donor testing, together with routine syphilis serology for hospital admissions, clinic attendees, jail inmates, and immigrants. In contrast with the post-first world war era these initiatives were brilliantly maintained, so that between 1945 and 1955 over two million Americans were treated for syphilis. As in the United Kingdom, post-war prevalence peaked and then dropped sharply to an all time low in 1955. However, in 1951 there were still 150000 confirmed cases, 14000 congenital infections, 6000 syphilitic mental hospital admissions, and 13000 adult deaths. ${ }^{22}$

Case finding was also further increased by contact tracing leading to treatment of up to $22 \%$ of men and $40 \%$ of women. ${ }^{23}$ In terms of disease stage, contact tracing provided $25 \%$ of all primary and secondary cases, $29 \%$ of early latent cases, $25 \%$ of congenital cases, and $18 \%$ of cases of late syphilis. ${ }^{24}$ These results led to increased federal funding and the nationwide appointment of public health administrators, originally called epidemiologists, who managed the clinics in the absence of trained medical staff.

MAINTAINING CONTROL (1956-2000)

With the 1955 nadir came the view that syphilis was a "dying disease" although the number of early infectious cases soon began to climb again. Optimistic views prevailed, federal support fell, and serological surveillance became less rigidly pursued. This happened despite a new "cluster testing" initiative of social as well as sexual contacts. ${ }^{25}$

Figures published in 1963 showed that of those with untreated syphilis, one in 200 would become blind, one in 44 insane, and one in 25 crippled. ${ }^{26}$ Calls were made for the strengthening of contact tracing and improved medical training but in fact many clinic hours were reduced. ${ }^{27} 28$

In 1964, however, William J Brown, then head of the VD division at the Center for Disease Control (CDC) in Atlanta, presented his proposals for the eradication of syphilis by 1972. He believed that if $30 \%$ of the newly infected were treated before their disease was transmitted, success would be assured. The cooperation of the private physician was vital, so all reactive serology from public and private laboratories was to be reported to local VD control programme directors for action. ${ }^{29}$ Sadly, although private physicians saw over $80 \%$ of all primary and secondary syphilis in the United States they reported only $12 \%$ and 
as a consequence funding between 1968 and 1971 remained at 1965 levels. Personnel had to be dropped from the eradication task force and so federal coordination was weakened. ${ }^{30}$

With diminishing yields, the cost effectiveness of screening came to be questioned in the late 1970 s. $^{31}$ It was pointed out, however, that although serology alone produced a low yield of early syphilis, the ensuing epidemiological methods brought to treatment $44 \%$ of the nation's infectious syphilis cases. In addition, serological screening identified $38 \%$ of late and late latent cases, and failure to maintain this surveillance would result in an increase in the costly late forms of the disease. Furthermore, the numbers of infectious cases had been increasing while serological surveillance was in progress, so dismantling it was unlikely to prove helpful. ${ }^{32} 33$

In the late 1980 s and early 1990 s there was a resurgence of syphilis in some southern states and deprived urban areas of the northern states, ${ }^{34}$ primarily among heterosexuals of black and Hispanic ethnic origin, and associated with "crack" cocaine use and the prevalence of prostitution. ${ }^{35}$ An increased incidence of syphilis was also seen in those with HIV infection. ${ }^{36}$

However, the CDC has reported a fall in the national rate of syphilis infection in the United States for 1998. A total of 6993 cases of primary and secondary syphilis were recorded, a decrease of $86 \%$ since 1990 and the lowest number recorded since 1941. As before, these cases were concentrated in the southern counties, non-Hispanic blacks were overrepresented, and focal outbreaks continued to occur. $^{37}$

\section{Future prospects}

Currently in the United Kingdom syphilis may be said to be under control. Routine serological surveillance continues in genitourinary medicine and antenatal clinics, and at the blood transfusion service. The situation in the United States is somewhat different and syphilis continues to be a thorn in the side of the public health services. Intermittent local epidemics have led only to renewed medical interest in the disease rather than to heightened public awareness.

However, social conditions may change rapidly and it may be more clinically and cost effective to use mathematical models, epidemiological approaches and ethnographic data to target core groups at risk rather than screen whole populations. ${ }^{38}$

A social model may better suit the situation in which there are 40000 syphilitic pregnancies associated with crack cocaine usage and prostitution, increased urbanisation and poverty, together with marital and family disintegration. ${ }^{39}$ Social factors have also been implicated in the persistence of syphilis infection where traditional partner notification procedures failed. In this situation it may be more appropriate to concentrate on the response to, rather than the prevention of, disease outbreaks. ${ }^{40}$
Continuing partner notification methods are a necessity in some situations and cluster identification of contacts and empirical treatment may also have their place. ${ }^{41}$ Patchy reliability of sexual histories in "high risk" populations has been noted, ${ }^{42}$ so it seems that the optimal control strategy may need to be varied according to the population characteristics. ${ }^{43}$ A variant of the partner notification method, social network analysis, has been a tacit assumption of STD control efforts for some decades. ${ }^{44}$ Initially developed to evaluate models of disease dynamics and resource issues, it has been used in the United States to control outbreaks in two settings, and confirms that syphilis is a "neighbourhood disease. ${ }^{\$ 5}$

\section{Conclusion}

All the above methods call for serious consideration at this time since history teaches that the prevalence of some diseases is determined by the socioeconomic structure of a society and how that structure functions. Pertinent examples include the Russian Federation and elsewhere in eastern Europe where the breakdown in public services has been accompanied by a resurgence of syphilis that is threatening to spread westwards across Europe.

Thus, with changing social structures and economic patterns, particularly in large urban populations, adaptability to changing times would seem to hold the key to future prospects for disease control. Efforts for the 21st century should therefore aim to use variable strategies tailored to the characteristics of the populations in which syphilis is to be controlled, together with the maintenance of widespread serological screening.

Contributors: RSM had the idea for the article and provided notes on the early strategies; TG updated the UK and MDT the USA sections; TG then put it all together and checked and inserted the references and wrote the final version.

1 Harrison LW. Some lessons learnt in 50 years' practice in venereology. Br F Vener Dis 1954;30:184-90.

2 MacFarlane WV. Treatment of syphilis during pregnancy. Lancet 1950;1069-70.

3 Burgess JA. Case finding through ante-natal serological tests for syphilis. Br F Vener Dis 1966;42:116-18.

4 MacFarlane WV, Johns HM, Schofield CBS. Background of congenital syphilis. Br $\mathcal{F}$ Vener Dis 1955;31:204-9.

5 Laird SM. Elimination of congenital syphilis. Br $\mathscr{f}$ Vener Dis 1959;35:15-19.

6 British Co-operative Clinical Group. Primary and secondary syphilis. Country of origin study, 1965. Br f Vener Dis 1967;43:89-95.

7 British Co-operative Clinical Group. Homosexuality and venereal disease in the United Kingdom. A second study. $\mathrm{Br}$ 7 Vener Dis 1980;56:6-11.

8 Ratcliffe L, Nicoll A, Carrington D, et al. Reference laboratory surveillance of syphilis in England and Wales, 1994 tory surveillance of syphilis in England and Wa

9 Stall R. How to lose the fight against AIDS among gay men. Stall R. How to lose the fight against AIDS among gay men.
Declare victory and leave the field. BMf 1994;309:685-6. Communicable Disease Surveillance Centre. Sexually transmitted diseases quarterly report: Syphilis in England transmitted diseases quarterly report: Syphilis in England 1997;7:192-4

11 Communicable Disease Surveillance Centre. An outbreak of infectious syphilis in Bristol. Communicable Disease Report. CDR Weekly 1997;7:291.

12 Battu VR, Horner PJ, Taylor PK, et al. Locally acquired heterosexual outbreak of syphilis in Bristol. Lancet 1997;350 $1100-1$

13 Communicable Disease Surveillance Centre. Syphilis in Bristol 1997-8: an update. Communicable Disease Report. CDR Weekly 1998;8:413, 416

14 Sherrard J, Luzzi G, Edwards A. Imported syphilis and other sexually transmitted infections among UK travellers other sexually transmitted infections among UK tra

15 Deayton J, French P. Incidence of early syphilis acquired in Deayton J, French P. Incidence of early syphilis acquired in
former Soviet Union is increasing. BMf 1997;315:1018 19. 
16 Tichonova L, Borisenko $\mathrm{K}$, Ward $\mathrm{H}$, et al. Epidemics of syphilis in the Russian Federation: trends, origins, and priorities for control. Lancet 1997;350:210-13.

17 STD Section, HIV and STD Division, PHLS Communicable Disease Surveillance Centre, with the PHLS Syphilis Working Group. Report to the National Screening Committee. Antenatal syphilis screening in the UK: A systematic review and national options appraisal with recommendations. London: Public Health Laboratory Service, 1998.

18 Communicable Disease Surveillance Centre. Increased transmission of syphilis in Manchester. Communicable Disease Report. CDR Weekly 2000;10:89

19 Communicable Disease Surveillance Centre. Increased transmission of syphilis in men who have sex with men reported from Brighton and Hove. Communicable Disease Report. CDR Weekly 2000;10:177,180

20 Brown WJ, Donohue JF, Axnick NW, et al. Syphilis and other venereal diseases. Cambridge, MA: Harvard University Press, 1970.

21 Parran T. Shadow on the land. New York: Reynal and Hitchcock, 1937

22 Aufranc WH. Are venereal diseases disappearing? Over-all picture throughout the country. Am $\mathcal{F}$ Syphilis 1951;5:1357.

23 Wright JJ, Sheps CG. Reports of the North Carolina syphilis studies 1 . An evaluation of case-finding measures in syphilis control. $\mathcal{F}$ Vener Dis Inform 1949;30:35-51.

24 Bauer TJ. Contact investigation of syphilis. F Vener Dis Inform 1949;30:339-40.

25 United States Department of Health, Education and Welfare. Public Health Service Publication 918. The eradication of syphilis. World forum on syphilis. Public Health Reports 1963;78:295-304.

26 Kampmeier RH. Responsibility of a physician in a program for eradication of syphilis. $7 A M A$ 1963;183:1094-8.

27 Frye WW. The importance of contact investigation in the control of syphilis. Med Clin N Am 1964;48:637-51.

28 Editorial. Reports by physicians called key to eradication of VD. $¥ A M A$ 1964;190:35-6.

29 Brown WJ. Status and control of syphilis in the United States. F Infect Dis 1971;124:428-33.
30 Felman YM. Should premarital syphilis serologies continue to be mandated by law? $7 A M A$ 1978;240:459-60.

31 Center for Disease Control, VD Control Division. Sexually transmitted disease (STD) statistical letter. Issue 127, 1978.

32 Center for Disease Control, VD Control Division. The quarterly epidemiological report of venereal diseases. March 1979.

33 United States Public Health Service. Sexually transmitted disease surveillance 1995. Atlanta, GA: Centers for Disease Control and Prevention, 1996.

34 Marx R, Aral SO, Rolfs RT, et al. Crack, sex, and STD. Sex Transm Dis 1991;18:92-101.

35 Rolfs RT. Treatment of syphilis, 1993. Clin Infect Dis 1995; 20 (suppl 1):S23-38.

36 Centers for Disease Control and Prevention. Summary of notifiable diseases, United States, 1998. MMWR 1999;47: $1-93$.

37 Catchpole MA. The role of epidemiology and surveillance systems in the control of sexually transmitted diseases. Genitourin Med 1996;72:321-9.

38 Nakashima AK, Rolfs RT, Flock ML, et al. Epidemiology of syphilis in the United States, 1941-1993. Sex Transm Dis 1996;23:16-23.

39 St Louis ME, Farley TA, Aral SO. Untangling the persistance of syphilis in the south. Sex Transm Dis 1996;23:1-4.

40 Gunn RA, Harper SL. Emphasizing infectious syphilis partner notification. Sex Transm Dis 1998;25:218-19.

41 Ellish NJ, Weisman CS, Celentano D, et al. Reliability of partner reports of sexual history in a heterosexual population at a sexually transmitted diseases clinic. Sex Transm Dis 1996;23:446-52.

42 Peterman TA, Toomey KE, Dicker LW, et al. Partner notification for syphilis. A randomized controlled trial of three approaches. Sex Transm Dis 1997;24:511-18.

43 Rothenberg R, Narramore J. The relevance of social network concepts to sexually transmitted disease control. Sex Transm Dis 1996; 23:24-9.

44 Rothenberg RB, Sterk C, Toomey KE, et al. Using social network and ethnographic tools to evaluate syphilis transmission. Sex Transm Dis 1998; 25:154-60. 